Endocrinol. Japon. 1988, 35 (5), 705-708

\title{
Anterior Pituitary Cell Antibodies Detected in Hashimoto's Thyroiditis and Graves' disease
}

\author{
Isao KOBAYASHI ${ }^{1}$, ToSHIHIKo INUKAI ${ }^{2}$, MASAKI TAKAHASHI ${ }^{2}$, \\ AKIRA ISHII ${ }^{2}$, KiHACHI OHSHIMA ${ }^{2}$, MaSaTOMO MORI ${ }^{2}$, \\ YoHNOSUKE SHIMOMURA ${ }^{1}$, SETSUO KOBAYASHI ${ }^{2}$, \\ Atsushi HASHIMOTO ${ }^{3}$ AND MASAhIKo SUGIURA ${ }^{3}$
}

Division of Endocrinology, Department of Medicine ${ }^{1}$ and First Department
of Internal Medicine $e^{2}$, Gunma University School of Medicine,
Maebashi 371, and Sohgo Biomedical Laboratories ${ }^{3}$, Kawagoe 350, Japan

\begin{abstract}
An immunofluorescence study using unfixed cryostat sections of rat pituitary glands was carried out on sera from 34 patients with Hashimoto's thyroiditis, 28 patients with Graves' disease, 10 patients with thyroid adenoma and 50 healthy subjects. After absorption of sera with rat liver tissues, 19 of 34 patients retained reactivity to anterior pituitary cell antibodies (PCA, $55.8 \%)$. On the other hand, immunofluorescence in anterior pituitary cells was faint and detected in only 2 of 28 patients with Graves' disease (7.1\%) after absorption of their sera with rat liver aceton powder. A similar result was also obtained when PCA were compared in the sera of Hashimoto's thyroiditis and Graves' disease with high titers of thyroid microsomal autoantibodies. PCA were detected neither in the sera of patients with thyroid adenoma nor in the healthy subjects.

The present study suggests that PCA were considerably more prevalent in Hashimoto's thyroiditis than in Graves' disease.
\end{abstract}

Pituitary cell antibodies (PCA) were frequently observed with isolated ACTH deficiency and insulin-dependent diabetes mellitus by immunofluorescence assay using cryostat sections of human pituitary gland (Mirakian et al., 1982; Populard, 1982). This suggests that an autoimmune process may be implicated as one of the pathogenic factors in these disorders. On the other

\section{Received March 9, 1988}

The address of the principal author: ISAO KOBAYASHI, M. D., Division of Endocrinology, Department of Medicine, Gunma University Hospital, Maebashi 371, Japan hand, evidence is accumulating to suggest that both Hashimoto's thyroiditis and Graves' disease may be a representative disease associated with an autoimmune basis (Calder and Irvine, 1975 ; Volpe et al., 1974; Volpe, 1977; Okita et al., 1981). However, little attention has been paid so far to the prevalence of PCA in Hashimoto's thyroiditis and Graves' disease.

The aim of the present study was to determine the prevalence of PCA in patients with Hashimoto's thyroiditis as compared to Graves' disease. 


\section{Materials and Methods}

\section{Sera}

Sera were collected from 34 patients with Hashimoto's thyroiditis, 28 patients with Graves' disease and 10 patients with nontoxic thyroid adenoma. Fifty healthy subjects served as controls. Aliquots of the sera were absorbed with liver aceton powder $(100 \mathrm{mg} / \mathrm{ml}$ serum $)$ at $4^{\circ} \mathrm{C}$ for $24 \mathrm{hr}$.

\section{PCA assay by biotin-avidin system}

PCA were assayed by the method of Sugiura et al., (1986). The anterior pituitary glands were obtained from Wistar male rats. Unfixed $5 \mu \mathrm{m}$ cryostat sections were used for the study. Aliquots of serum $(25 \mu \mathrm{l})$, after absorption with rat liver aceton powder, were added to sections on slides and kept for $30 \mathrm{~min}$ at room temperature in a humidified chamber. They were washed twice with PBS (pH 7.4). Twenty-five $\mu \mathrm{l}$ biotinylated anti-human IgG solution $(0.5$ $\mathrm{mg} / \mathrm{ml}$ PBS, Vector Lab. Inc., Calif.) was then added to the sections and slides were kept for $30 \mathrm{~min}$ at room temperature. After washing twice with PBS (pH 8.0), $25 \mu$ l of FITC-labeled avidin solution $(0.167 \mathrm{mg} / \mathrm{ml}$ PBS, Vector Lab, Inc.) was added to the sections and incubated at room temperature for an additional $30 \mathrm{~min}$. After three washings with PBS, the sections were examined under an incident fluorescence microscope (Olympus BH-2).

\section{Thyroid autoantibody assays}

Thyroid microsomal autoantibodies (MHA) were assayed by passive microhaemagglutinin (Fujizoki, Tokyo). Antithyroglobulin antibodies also were measured with a commercially available kit (Fujizoki, Tokyo).

\section{Diagnosis of thyroid diseases}

Diagnosis of Hashimoto's thyroiditis and Graves' disease was based on the clinical history, the presence of diffuse goiter, thyroid autoantibodies, and serum $\mathrm{T}_{4}, \mathrm{~T}_{3}$ and $\mathrm{TSH}$ concentrations. The patients with Graves' disease were untreated at the time of the study. Thyrotropinbinding inhibitor immunoglobulins (TBII) were assayed with a commercially available kit (Smith and Hall, 1974). All of the patients with Hashimoto's thyroiditis had been receiving $\mathrm{L}-\mathrm{T}_{4}(100$ $\mu \mathrm{g} /$ day) orally for periods varying from 6 months to 60 months. None of the patients had definite hypothyroidism prior to treatment. Diagnosis of thyroid adenoma was made from the findings including scintiscan, aspiration cytology and ultrasound studies on thyroid. Serum $\mathrm{T}_{4}$ was measured with a RIA kit (Daiichi Radioisotope Labo., Tokyo). Serum $\mathrm{T}_{3}$ and TSH were determined as previously (Kobayashi et al., 1980). Statistical evaluation was made by $\mathrm{X}^{2}$-test.

\section{Results}

Sera from the patients with Hashimato's thyroiditis, Graves' disease, thyroid adenoma and healthy subjects were tested for antibodies to anterior pituitary cells by this biotin-avidin system employing rat pituitary cryostat sections. The results are summarized in Table 1. After absorption of sera with rat liver tissues, 19 of 34 patients with Hashimoto's thyroiditis retained reactivity to anterior pituitary cells $(55.8 \%)$. On the other hand, immunofluorescence was faint and detected in only 2 of 28 patients with Graves' disease (7.1\%) after absorption of

Table. 1. Prevalence of pituitary cell antibodies (PCA) in patients with thyroid diseases and healthy subjects

\begin{tabular}{lccc}
\hline \multirow{2}{*}{ Group } & \multirow{2}{*}{ No. of patients } & \multicolumn{2}{c}{ No. of positive PCA } \\
\cline { 3 - 4 } & & MHA $<25600 \times$ & MHA $\geqq 25600 \times$ \\
\hline Hashimoto's thyroidtis & 34 & $1(2.9)$ & $18(52.9) \# *$ \\
Graves' disease & 28 & $0(0)$ & $2(7.1)$ \\
Thyroid adenoma & 10 & $0(0)$ & $0(0)$ \\
Healthy subjects & 50 & $0(0)$ & $0(0)$ \\
\hline
\end{tabular}

\# The results after absorption of sera with rat liver aceton powder are shown.

* p $<0.05$ vs. Graves' disease. 
sera with rat liver aceton powder. In contrast, 10 sera from thyroid adenoma patients and 50 healthy subjects were all negative on PCA assay. PCA were tentatively compared in the sera of Hashimoto's thyroiditis and Graves' disease with relatively high titers of MHA $(\mathrm{MHA} \geqq 25600 \times)$. The prevalence of PCA was significantly higher in the sera of the patients with Hashimoto's thyroiditis than that of Graves' disease $(\mathrm{p}<0.05)$.

\section{Discussion}

The autoimmune nature of destructive hypoyhysitis has been suspected since 1962 (Goudies and Pinkerton, 1962), but the evidence of PCA had been scarce. Pouplard (1982) reported that 2 of 19 patients with panhypopituitarism were positive for PCA on rat or guinea pig. Many investigators reported that isolated ACTH deficiency was associated with Hashimoto's thyroiditis (Goudie and Pinkerton, 1962; Hume and Robert, 1967; Richtsmeier et al., 1980). Kojima et al., (1982) described a case of isolated ACTH deficiency associated with polyglandular failure.

In the present study, we have assayed PCA in the three thyroid diseases, determined by fluorescence with unfixed cryostat sections of rat pituitary gland. After absorption of sera with rat liver aceton powder, the prevalence of PCA was $55.8 \%$ in the sera of patients with Hashimoto's thyroiditis. In contrast, immunofluorescence in the sera of patients with Graves' disease was faint and almost disappered following the addition of rat liver tissues. A similar result was obtained when PCA-positive patients with relatively high titers of MHA from the two autoimmune thyroid diseases were compared (Table 1). It is possible that PCA may often be associated with thyroid autoantibodies. The effect of the absorption of patient sera with human thy- roid aceton powder was also examined. Immunofluorescence in anterior pituitary cells was still observed (data not shown). These results suggest that PCA were considerably more prevalent in Hashimoto's thyroiditis than in Graves' disease.

The present investigation does not discriminate between the cell type abnormalities of the pituitary gland. Nevertheless, our data lend support to the concept that sometimes Hashimoto's thyroidities may extend to endocrine organ specific involvement when sera contain the organ specific antibodies (Volpé et al., 1974; Volpé, 1977). Further studies are needed to see if there are some abnormalities in the hypothalamopituitary axis in PCA-positive patients, particularly those with Hashimoto's thyroiditis.

\section{References}

Calder, E. A. and W. J. Irvine (1975). Cell mediated immunity and immune complexes in thyroid diseases. J. Clin. Endocrinol. Metab. 41, 287-318.

Goudie, R. B. and R. H. Pinkerton (1962). Anterior hypophysitis and Hashimoto's thyroiditis in a young woman. J. Path. Bact. 83, 584-588.

Hume, R. and G. H. Robert (1967). Hypophysitis and hypopituitarism: Report of a case. Brit. Med. J. 2, 548-550.

Kobayashi, I., Y. Shimomura, S. Maruta, K. Ohshima, M. Mori, N. Kamio and H. Fukuda (1980). Clofibrate and a related compound suppress TSH secretion in primary hypothyroidism. Acta Endocrinol. 94, 53-57.

Kojima, I., I. Nejima and E. Ogata (1982). Isolated adrenocorticotropin deficiency associated with polyglandular failure. J. Clin. Endocrinol. Metab. 54, 182-186.

Mirakian, R., A. G. Cudworth, G. F. Bottazzo and C. A. Richardson (1982). Autoimmunity to anterior pituitary cells and the pathogenesis of insulin-dependent diabetes mellitus. Lancet 2, 755-759.

Okita, N., V. V. Row and R. Volpé (1981). Suppressor T-lymphocytes deficiency in Graves' disease and Hashimoto's thyroiditis. J. Clin. 
Endocrinol. Metab. 52, 528-533.

Populard, A. (1982). Pituitary autoimmunity. Horm. Res. 16, 289-297.

Richtsmeier, A. J., R. A. Henry, J. M. B. Bloodworth and E. N. Ehrlich (1980). Lymphoid hypophysitis and selective adrenocorticotropic hormone deficiency. Arch. Intern. Med. 140, 1243-1245.

Smith, B. R. and R. Hall (1974). Thyroidstimulating immunoglobulin in Graves' disease. Lancet 2, 427-430.

Sugiura, M., A. Hashimoto, M. Shizawa, M. Tsukada, S. Maruyama, T. Ishido, T. Kasa- hara and Y. Hirata (1986). Heterogeneity of anterior pituitary cell antibodies detected in insulin-dependent diabetes mellitus and adrenocorticotropic hormone deficiency. Diabetes Res. 3, 111-114.

Volpé, R., N. R. Fsrid, C. V. Westarp and V. V. Row (1974). The pathogenesis of Graves' disease and Hashimoto's thyroiditis. Clin. Endocrinol (Oxf). 3, 239-261.

Volpé, R. (1977). The role of autoimmunity in hypoendocrine and hyperendocrine function. Ann. Intern. Med. 87, 86-99. 